\section{Preliminary study on physicochemical and biochemical stress markers at poultry slaughterhouse}

\section{Serena Santonicola, \\ Maria Francesca Peruzy, \\ Mariagrazia Girasole, Nicoletta Murru, Maria Luisa Cortesi, Raffaelina \\ Mercogliano}

Department of Veterinary Medicine and Animal Production, University of Naples, Italy

\begin{abstract}
Pre-slaughter stress can result in variations in the glycogen storage and metabolic changes of muscle, responsible for quality poultry meat. Aim of this study was to investigate, as pre-slaughter stress markers and quality meat, physicochemical $(\mathrm{pH})$, biochemical (muscle glycogen content), and chemical (super oxides free radicals) parameters. The carcass quality, as incidence of individual carcass defects, was also evaluated. Twenty broilers were processed with two different electrical stunning: high $(250 \mathrm{~Hz} ; 640 \mathrm{~mA} ; 60 \mathrm{~V})$ (Lot $\mathrm{C}$ or control) and low (150 Hz; $360 \mathrm{~mA} ; 60 \mathrm{~V})$ (Lot A) frequency and intensity, using sinusoidal alternating current. As preliminary results, the use of low frequency and intensity induced faster $\mathrm{pH}$ decline post mortem and adequate acidification of $\mathrm{pH}$ at 3 hours (6.49 Lot C; 6.37 Lot A), better muscle glycogen reserve $(0.770 \mu \mathrm{L} / 50 \mathrm{~mL}$ Lot $\mathrm{C}$; $1.497 \mu \mathrm{L} / 50 \mathrm{~mL}$ Lot $\mathrm{A}$ ), and lightly more rapid muscle oxidation (IDF: 0.109 Lot C; 0.122 Lot A), (FOX: $0.131 \mathrm{MeqO}_{2} / \mathrm{kg}$ Lot C; $0.140 \mathrm{MeqO}_{2} / \mathrm{kg}$ Lot A). The incidence of individual carcass defects sufficient to cause downgrading or rejection, both in Lot $\mathrm{C}$ and Lot $\mathrm{A}$, was generally low. In a multidisciplinary approach, to assess animal welfare and quality poultry meat, additional and feasible parameters should be implemented. Monitoring of $\mathrm{pH}$, muscle glycogen reserve and superoxide free radical production measurements might be markers easier to use, routinely, in practice at abattoir. Further studies are needed to evaluate the usefulness of these parameters.
\end{abstract}

\section{Introduction}

Council Regulation 1099/2009/EC (European Commission, 2009) on the protection of animals at the time of killing sets out rules governing the killing of animals kept for the production of food. The electrical stunning induce a lack of consciousness and sensibility before the animals are killed, and is the most accepted method to immobilize the poultry before slaughter (Bilgili, 1999). The use of a minimum current of 120 $\mathrm{mA}$ causes cardiac arrest in $90 \%$ of the birds and instantaneous and irreversible stunning. Nevertheless, the electrical stunning may represent serious concern about the welfare of broilers and quality meat (Gregory, 2008; Grandin, 2010). Intensity of electric current used for stunning can vary among slaughterhouses (Kissel et al., 2015). The time of unconsciousness increases with increasing stunning voltage, but at the same time the extent of carcass damage may be aggravated, while the incidence of ventricular fibrillation and death increase (Gregory and Wotton, 1990; EFSA, 2004). On the other hand, a high frequency can increase the depth of unconsciousness, but the duration of unconsciousness decreases as the stunning frequency increases (Huang et al., 2014; Kannan et al., 1997; Mouchoniere et al., 1999). The final quality of meat depends on the voltage, frequency, and duration of the electrical stunning. As preslaughter stress conditions, hanging operations, exposure to heat during the preslaughter period, and stunning can lead to rapid glycolysis ( $\mathrm{pH}$ drop) (Petracci et al., 2010), low pH (Rammouz et al., 2004; Van Hoff, 1979) and muscle cytotoxicity in chicken broilers (Debut et al., 2005; Kannan et al., 1997; Loschi et al., 2004; Petracci et al., 2010). At the slaughterhouse, a potential indicator of animal welfare is the absence of stress, but there is no standard definition of stress and no single biochemical assay system to measure stress (Velarde et al., 2010). The return of eye reflexes and rhythmic breathing are clinic indicators of the early return of the functions of the brain after electrical stunning (von Holleben et al., 2010). The high level of plasma corticosterone is a biochemical indicator of stress in birds (McFarlane and Curtis, 1989; $\mathrm{Xu}$ et al., 2011). Presently, Electrocardiogram (ECG) and Electroencephalogram (EEG) are considered indicators of unconsciousness and insensibility, nevertheless may not be practical methods to ascertain, routinely, the effectiveness of the stun at the abattoir (EFSA, 2012). For these reasons, studies on effective stunning should be validated by measures easier to use practically at poultry abattoir to assess animal welfare and quality meat (Gregory, 2008; Mercogliano et al., 2016).

Aim of the study was to investigate the feasibility of physicochemical, chemical and biochemical parameters to evaluate pre-
Correspondence: Raffaelina Mercogliano, Department of Veterinary Medicine and Animal Production, University of Naples Federico II, via F. Delpino, 1, 80137 Naples, Italy.

Tel: +39.081.2536062 - Fax: +39.081.458683 E-mail: raffaella.mercogliano@unina.it

Key word: Poultry meat; Animal welfare; Stress markers.

Conflict of interest: the authors declare no potential conflict of interest.

Received for publication: 14 October 2016. Revision received: 12 December 2016. Accepted for publication: 16 December 2016.

This work is licensed under a Creative Commons Attribution-NonCommercial 4.0 International License (CC BY-NC 4.0).

CC Copyright S. Santonicola et al., 2017

Licensee PAGEPress, Italy

Italian Journal of Food Safety 2017; 6:6346

doi:10.4081/ijfs.2017.6346

slaughter stress and quality meat in broilers processed using two electrical stunning treatments.

\section{Materials and Methods}

Two experiments were conducted, using N. 20 Ross commercial broilers (aged 56 days, with an average weight of $2.5 \mathrm{~kg}$ ), obtained from a conventional poultry farm. The broilers were given ad libitum access to a standard diet throughout the period of growth (Council Directive 2007/43/EC; European Commission, 2007).

The animals were subjected to a 12 hour fasting period, prior to their slaughter (Council Directive 2007/43/EC; European Commission, 2007). They were transported to an authorized EC slaughterhouse within a 30 minute, to prevent the detrimental effects of a long journey on the welfare state (Council Regulation 1/2005/EC; European Commission, 2005). The birds were randomly divided into 4 groups of 5 animals. For each slaughter N. 5 of birds of Lot C (or control) were subjected to a stunning treatment at $250 \mathrm{~Hz} ; 640 \mathrm{~mA} ; 60 \mathrm{~V}$ (high frequency and intensity), and N. 5 of birds of Lot $\mathrm{A}$ at $150 \mathrm{~Hz} ; 360 \mathrm{~mA}$; $60 \mathrm{~V}$ (low frequency and intensity current). At the slaughterhouse ante-mortem inspection was carried out by an official veterinarian to evaluate the welfare conditions and health status in birds (Council Regulation 854/2004/EC; European Commission, 2004). The electrical stunning was conduct- 
ed using sinusoidal alternating current (AC) in accordance with the minimum currents laid down (Reg. 1099/09/EC, Annex I, Chapter II, point 6.3), and the total stunning duration was 4 seconds.

The broilers were individually shackled from head to feet. The duration of shackling before stunning was kept to 2 minutes, and a blue light intensity (50 lux) was used to calm the animals. In a multi-bird water bath stunning (Cattaruzzi S02POL, Italy) the head of broilers of Lots $\mathrm{C}$ and $\mathrm{A}$ was brought in contact with an electric grid submerged in a saturated brine solution.

According to the experimental design all the birds were killed by the same operator, using a conventional unilateral neck cut, severing the carotid artery and jugular vein, and is allowed to bleed for 150 seconds, based on the following sequence: -birds of Lot C; -birds of Lot A.

The $\mathrm{pH}$ of Pectoralis major was measured immediately after the slaughter at 0.25 hours $(\mathrm{pH} 0), 3$ hours $(\mathrm{pH})$ and $24 \mathrm{~h}$ (pHu). Shortly after for chemical and biochemical analysis a sample of carcass each from Pectoralis major and from Quadriceps femoris was chilled in a static ice, and then held packed.

The eviscerated birds were packed in polyethylene bags and placed in insulated boxes filled with ice for transport to the laboratory, within 3 hours from the time of slaughter. They were then refrigerated at 3 to $5^{\circ} \mathrm{C}$ for 24 hours, when the evaluations of carcass and meat defects were conducted. Appearance quality attributes, such as skin colour, meat colour, broken bones, appearance defects like bruises and haemorrhages were evaluated in each carcass.

The chemicals and solvents used in the study were obtained from Sigma-Aldrich, Germany. All solutions were prepared from reagent-grade chemicals. In each carcass, the $\mathrm{pH}$ of Pectoralis major was measured using a pH meter (Hanna pH 211, Hanna Instruments, Woonsocket, RI, USA). In particular, the $\mathrm{pH}$ at 3 hours was investigated as a marker of acute pre-slaughter stress in poultry, because it may correspond to the start of shelf life of poultry meat.

Muscle oxidation was evaluated accord-

Table 1. Poultry slaughter: carcass quality evaluation defects (\%) of Lot C (high frequency and intensity current) and Lot $A$ (low frequency and intensity current) carcasses.

\begin{tabular}{lcc} 
Score & Lot $\mathbf{C}$ & Lot A \\
0 & 80.2 & 84.5 \\
1 & 12.4 & 15.5 \\
\hline 2 & 7.4 & - \\
\hline
\end{tabular}

ing to Shantha and Decker (1994), homogenizing together a sample of Pectoralis major and Quadriceps femoris from each carcass. Superoxide free radical analysis was carried out following both the International Dairy Federation's method (IDF 74A, 1991), and the Ferrous Oxidation-Xylenol orange's (FOX) method. These methods are based on the oxidation of iron. In IDF method, the sample $(\leq 0.01-0.30 \mathrm{~g})$ was mixed in a disposable glass tube with $9.8 \mathrm{~mL}$ chloroformmethanol $(7+3, v / v)$ in a vortex mixer for 24 seconds. After that, ammonium thiocyanate solution $(50 \mu \mathrm{L})$ was added, and the sample was mixed in a vortex mixer for 2-4 seconds. Then, $50 \mu \mathrm{L}$ iron (II) solution was added and the sample was mixed in a vortex mixer for 2-4 seconds. After 5 minutes of incubation at room temperature, the absorbance of the sample was determined at $500 \mathrm{~nm}$ against a blank that contained all the reagents, except the sample, by using a spectrophotometer. The entire procedure was conducted in subdued light and completed within $10 \mathrm{~min}$. The FOX method (Shantha and Decker, 1994) was similar to the IDF method, except that, $0.01 \mathrm{~mol} / \mathrm{L}$ xylenol orange sodium salt solution in water was used as the complexing dye, instead of ammonium thiocyanate. Absorbance was determined at $560 \mathrm{~nm}$ after 5 minutes of incubation at room temperature. To construct the curve of $\mathrm{Fe}^{3+}$ concentration $\mathrm{v} / \mathrm{s}$ absorbance, a standard solution of iron (III) chloride $(10 \mu \mathrm{g} \mathrm{Fe} / \mathrm{mL})$ was prepared for both methods (Mehta et al., 2015). Glycogen concentration was determined by a coupled enzyme assay (SigmaAldrich, Saint Louis, MO, USA) which produces a colorimetric $(570 \mathrm{~nm})$ /fluorometric $(\lambda \mathrm{ex}=535 / \lambda \mathrm{em}=587 \mathrm{~nm})$ product, proportional to the glycogen present.

To prepare the standard for colorimetric detection $10 \mu \mathrm{L}$ of the $2.0 \mathrm{mg} / \mathrm{mL}$ Glycogen
Standard were diluted with $90 \mu \mathrm{L}$ of distilled water to prepare a $0.2 \mathrm{mg} / \mathrm{mL}$ standard solution. After that $0,2,4,6,8$, and $10 \mu \mathrm{L}$ of $0.2 \mathrm{mg} / \mathrm{mL}$ standard solution were added into a 96 well plate, generating 0 (assay blank), 0.4, 0.8, 1.2, 1.6, and $2.0 \mu \mathrm{g} /$ well standards. Hydrolysis Assay Buffer was added to each well to bring the volume to 50 $\mu \mathrm{L}$. For colorimetric assays, the absorbance was measured at $570 \mathrm{~nm}\left(\mathrm{~A}_{570}\right)$.

To prepare the standard for fluorimetric detection $10 \mu \mathrm{L}$ of the $2.0 \mathrm{mg} / \mathrm{mL}$ Glycogen Standard were diluted with $990 \mu \mathrm{L}$ of distilled water to prepare a $0.02 \mathrm{mg} / \mathrm{mL}$ standard solution. After that $0,2,4,6,8$, and 10 $\mu \mathrm{L}$ of the $0.02 \mathrm{mg} / \mathrm{mL}$ standard solution were added into a 96 well plate, generating 0 (assay blank), 0.04, 0.08, 0.12, 0.16, and $0.20 \mu \mathrm{g} /$ well standards. Hydrolysis Assay Buffer was added to each well to bring the volume to $50 \mu \mathrm{L}$. Fluorescence intensity was measured at $\lambda \mathrm{ex}=535 / \lambda \mathrm{em}=587 \mathrm{~nm}$

\section{Sample preparation}

Ten $\mathrm{mg}$ of tissue were homogenized in $100 \mu \mathrm{L}$ of water on ice. Homogenates were boiled for 5 minutes to inactivate enzymes. After that the samples were centrifuged at 13000 ' $g$ for 5 minutes to remove insoluble material. Hydrolysis Buffer was added to a final volume of $50 \mu \mathrm{L}$. For colorimetric assays, the absorbance was measured at 570 $\mathrm{nm}\left(\mathrm{A}_{570}\right)$. Fluorescence intensity was measured at $\lambda$ ex $=535 / \lambda \mathrm{em}=587 \mathrm{~nm}$. The sample blank value was subtracted from the sample readings to obtain the corrected measurement:

\section{$\mathrm{Sa} / \mathrm{Sv}=\mathrm{C}$}

where $\mathrm{Sa}$ is the amount of glycogen in unknown sample $(\mu \mathrm{g})$ from standard curve; $\mathrm{Sv}$ is the sample volume $(\mu \mathrm{L})$ added into the wells; and $\mathrm{C}$ is the concentration of glycogen

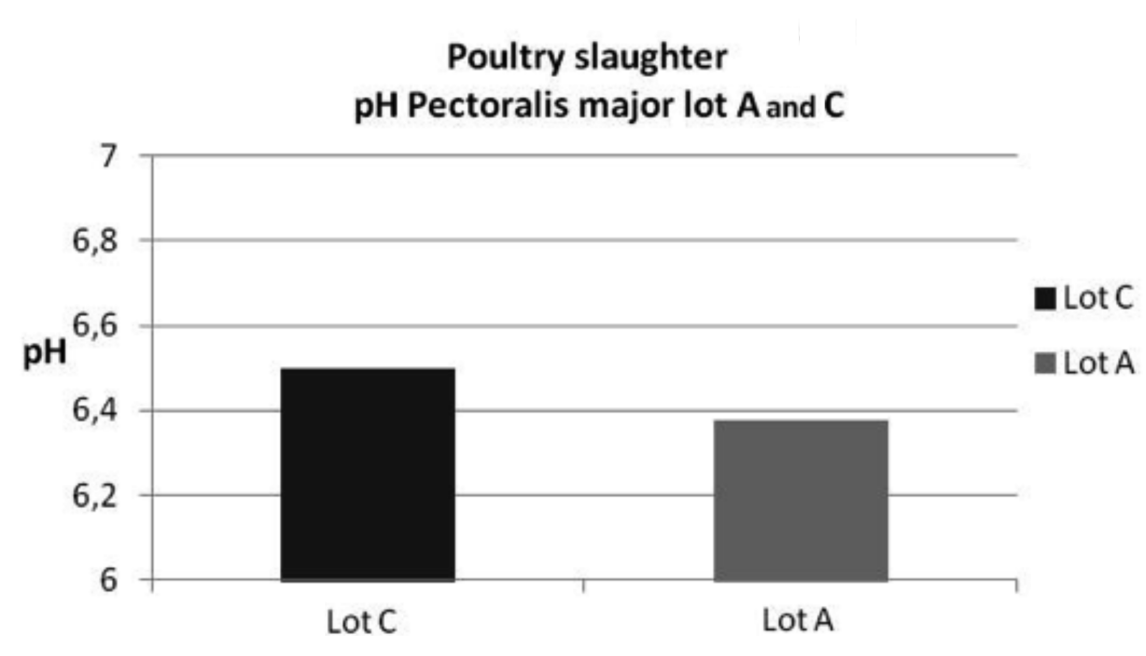

Figure 1. Poultry slaughter: $\mathrm{pH}$ values (mean) of Pectoralis major at $3 \mathrm{~h}$ of Lot A (low frequency and intensity current) and Lot $\mathrm{C}$ (high frequency and intensity stunning). 
in sample. To evaluate the carcass quality, the skin on the breast area was removed and several incisions were made along the breast, thus, the muscles were examined for superficial and internal (deep) defects. As appearance defects, i) skin colour, ii) meat colour, iii) broken bones, iv) bruises and v) hemorrhages in each carcasses were evaluated. The carcasses were scored from 0 to 2 for all conditions: a score of 0 indicated no defects; 1 slight to moderate defects; 2 severe defects. The percentage of carcasses with defects was calculated, using the ratio between the number of birds, showing specific defect, to the total number of birds examined.

\section{Results}

Data on physicochemical, chemical, biochemical parameters and evaluation of appearance carcass quality attributes are shown in Figures 1-3 and Table 1.

\section{Discussion}

At the end of the slaughter, pre-slaughter stress increases the concentration of lactate and lead to a rapid $\mathrm{pH}$ drop in Pectoralis major at 15 minutes until 6 hours postmortem, after which no difference is observed after 24 hours (Craig and Fletcher, 1997; Papinaho and Fletcher, 1996; Petracci et al., 2010).

According to literature, carcasses of Lots $\mathrm{C}$ and $\mathrm{A}$ stunned at high and low frequency and intensity showed a rapid $\mathrm{pH}$ drop in Pectoralis major at 15 minutes and up 3 hours post-mortem ( $\mathrm{pH} 6.49$ and 6.37, respectively). After 3 hours, and until 24 hours, no important differences were observed, even if $\mathrm{pH}$ values were slightly lower in the carcasses stunned at lower intensity and frequency conditions. The monitoring of $\mathrm{pH}$, in particular at 3 hours, might be considered a rapid and feasible measurement of pre-slaughter stress at slaughterhouse.

Pre-slaughter stress can lead to increase of oxidative activity and production of superoxides free radicals in the muscle of poultry (Shantha and Decker, 1994). Concentration of peroxide provides useful data on the degree of the muscle oxidation (Gregory, 1994; Mujahid et al., 2005; Shantha and Decker, 1994). The IDF and FOX data showed a slightly higher superoxide free radicals production in Lot $\mathrm{A}$, if compared to Lot $\mathrm{C}$ carcasses (IDF: Lot $\mathrm{C}$ $0.109 \mathrm{MeqO}_{2} / \mathrm{kg}$; Lot A $0.122 \mathrm{Meq} \mathrm{O}_{2} / \mathrm{kg}$ ) (FOX: Lot C $0.131 \mathrm{MeqO}_{2} / \mathrm{kg}$; Lot A 0.140 $\mathrm{MeqO}_{2} / \mathrm{kg}$ ). Under the experimental electric conditions, a more intense muscle oxidation was observed. In poultry muscle the measurement of superoxide free radicals production seems to be a sensible indicator of pre-slaughter stress related to stunning.

Glycogen concentration of Pectoralis major decreased in carcasses stunned with high frequencies showing a fast exhaustion of glycogen at the early post mortem examination, according to $\mathrm{Xu}$ et al. (2011). Preliminary results of the study showed that the use of lower intensity and frequency electrical conditions led to a major muscle glycogen reserve in Lot A carcasses than Lot control (Lot C $0.770 \mu \mathrm{L} / 50 \mathrm{~mL}$; Lot A $1.497 \mu \mathrm{L} / 50 \mathrm{~mL}$ ). For this reason, the lactate production increased and lower $\mathrm{pH}$ values were observed in Lot A carcasses.

High stunning frequencies may improve meat quality without aggregating stress,

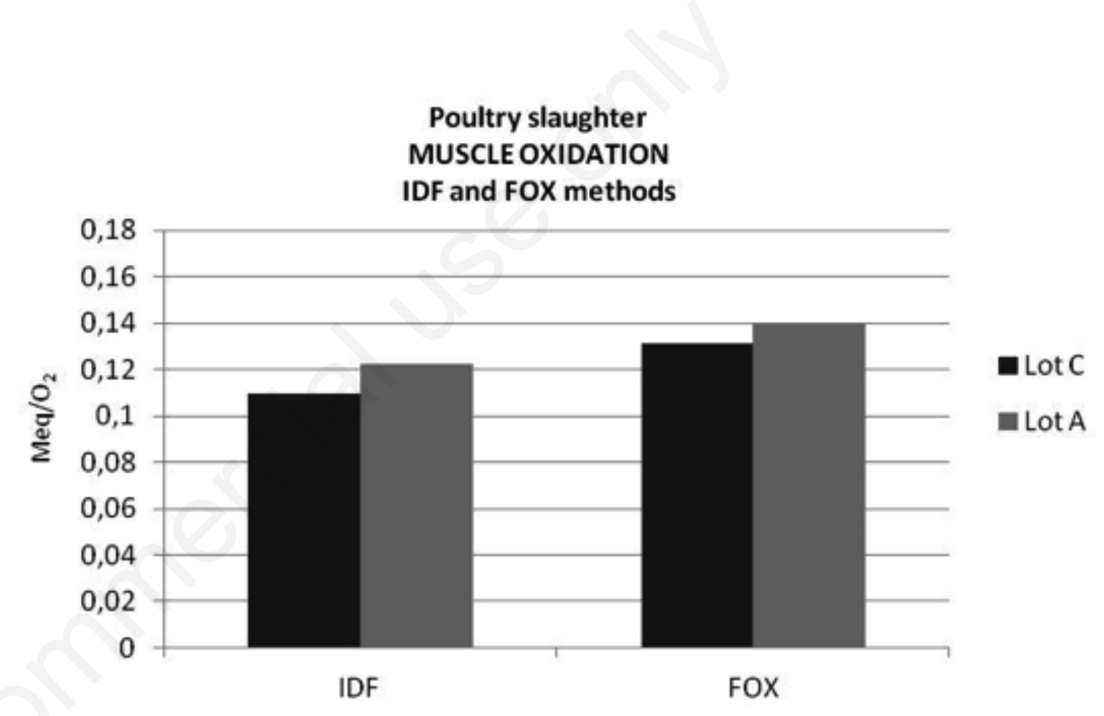

Figure 2. Poultry slaughter: superoxide free radicals values $\left(\mathrm{MeqO}_{2} / \mathrm{kg}\right)$ of Lot A (low frequency and intensity current) and Lot $\mathrm{C}$ (high frequency and intensity current).

\section{Poultry slaughter Pectoralis major glycogen Lot $\mathrm{A}$ and $\mathrm{C}$}

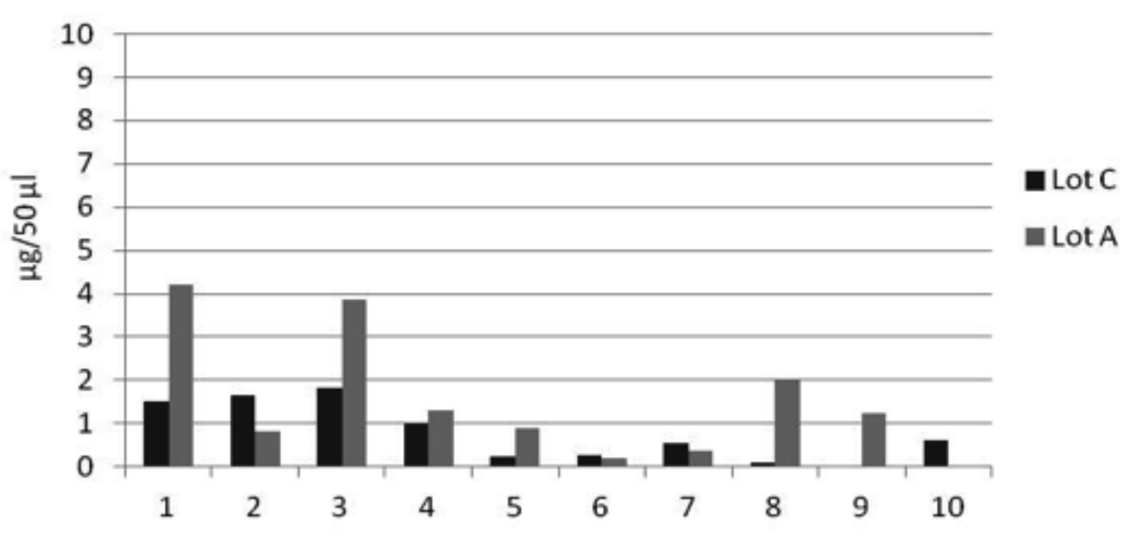

Figure 3. Poultry slaughter: muscle glycogen values $(\mu \mathrm{g} / 50 \mu \mathrm{L})$ of Lot $\mathrm{A}$ (low frequency and intensity current) and Lot $\mathrm{C}$ (high frequency and intensity current). 


\section{Conclusions}

At poultry slaughterhouse, monitoring of stunning efficiency through indicators should be carried out, to assure animal welfare and quality meat. Preliminary results of the study showed more acid values of $\mathrm{pH}$, a higher values of muscle glycogen reserve and muscle peroxidation in carcasses obtained by using a $360 \mathrm{~mA} / 150 \mathrm{~Hz}$ treatment. Using a multidisciplinary approach, the $\mathrm{pH}$ monitoring, measurement of superoxide radical production, and muscle glycogen evaluation might be additional and feasible measures, easier to use under practical conditions, to assess animal welfare and quality poultry meat.

\section{References}

Ali ASA, Lawson MA, Tauson AH, Jensen JF, Chwalibog A, 2007. Influence of electrical stunning voltages on bleed out and carcass quality in slaughtered broiler chickens. Arch Geflugeld 71:35-40.

Bilgili SF, 1999. Recent advances in electrical stunning. Poultry Sci 78:282-6.

Craig EW, Fletcher DL, 1997. A comparison of high current and low voltage electrical stunning systems on broiler breast rigor development and meat quality. Poultry Sci 76:1178-81.

Debut M, Berri C, Arnould C, Guemené D, Santé-Lhoutellier V, Baéza E, Jehl N, Jégo Y, Beaumont $C$, Le Bihan-Duval E, 2005. Behavioral and physiological responses of three chicken breeds to pre-slaughter shackling and acute heat stress. Brit Poultry Sci 46:527-535.

EFSA, 2004. Welfare aspects of stunning and killing methods. European Food Safety Authority, Parma, Italy.

EFSA, 2012. Scientific opinion on the electrical requirements for waterbath stunning equipment applicable for poultry EFSA Panel on Animal Health and Welfare (AHAW). EFSA J 10:2757.

European Commission, 2004. Regulation of the European Parliament and of the Council of 29 April 2004 laying down specific rules for the organization of official controls on products of animal origin intended for human consumption, 854/04/EC. In: Official Journal, L 226, 25.6.2004, p. 83.

European Commission, 2005. Regulation of the European Parliament and of the Council of 22 December 2004 on the protection of animals during transport and related operations and amending Directives 64/432/EEC and 93/119/EC and Regulation (EC) No 1255/97,
1/2005/EC. In: Official Journal, L 3/1, 5.1.2005.

European Commission, 2007. Council Directive of 28 June 2007 laying down minimum rules for the protection of chickens kept for meat production, 2007/43/EC. In: Official Journal, L 182/19, 12.7.2007.

European Commission, 2009. Regulation of the European Parliament and of the Council of 24 September 2009 on the protection of animals at the time of killing, 1099/2009/EC. In: Official Journal, L 303/30, 18/11/2009.

Grandin T, 2010. Auditing animal welfare at slaughter plants. Meat Sci 86:56-65.

Gregory NG, 1994. Preslaughter, handling, stunning and slaughter. Meat Sci 36:4556.

Gregory NG, 2008. Animal welfare at markets and during transport and slaughter. Meat Sci 80:2-11.

Gregory NG, Wotton S, 1990. An evaluation of the effectiveness of handheld stunners for stunning chickens. Vet Rec 126:290-1.

Huang JC, Huang M, Yang J, Wang P, Xu XL, Zhou GH, 2014. The effects of electrical stunning methods on broiler meat quality: effect on stress, glycolysis, water distribution, and myofibrillar ultrastructures. Poultry Sci 93:2087-95.

International Dairy Federation, 1991. International IDF standards, sec. 74A:1991. IDF, Brussels, Belgium.

Kannan G, Heath J, Wabeck CJ, Mench JA, 1997. Shackling of broilers: effects on stress response and breast meat quality. Brit Poultry Sci 83:323-32.

Kissel C, Soares AL, Oba A, Shimokomaki M, 2015. Electrical water bath stunning of broilers: effects on breast meat quality. Jpn Poultry Sci Assoc 52:74-80.

Loschi AR, Stocchi R, Rea S, Cecchini S, Galli R, 2004. Browning in turkey meat preparations and related changes in muscles after slaughtering. Morphpathological study. Ital J Food Sci 16:235-43.

McFarlane JM, Curtis SE, 1989. Multiple concurrent stressors in chicks. Effect on plasma corticosterone and the heterophil: lymphocyte ratio. Poultry Sci 68:522-7.

Mehta BM, Darji VB, Aparnathi KD, 2015. Comparison of five analytical methods for the determination of peroxide value in oxidized ghee. Food Chem 185:44953.

Mercogliano R, Santonicola S, Murru N, Paciello O, Pagano TB, Peruzy MF, Anastasio A, Cortesi ML, 2016. Study on the effects of electrical stunning parameters for broilers on biochemical and histological markers of stress and meat quality. Anim Prod Sci 57:1144-8.

Mouchoniere M, Le Pottier G, Fernandez $\mathrm{X}, 1999$. The effect of current frequency during waterbath stunning on the physical recovery and rate and extent of bleed out in turkeys. Poultry Sci 78:485-9.

Mujahid A, Yoshiki Y, Abika Y, Toyomizu M, 2005. Superoxide radical production in chicken skeletal muscle induced by acute heat stress. Poultry Sci 84:307-14.

Papinaho PA, Fletcher DL, 1996. The effects of stunning amperage and deboning time on early rigor development and breast meat quality of broilers. Poultry Sci 75:672-6.

Petracci M, Bianchi M, Cavani C, 2010. Preslaughter handling and slaughtering factors influencing poultry products quality. J World Poultry Sci 66:17-26.

Rammouz ER, Berri C, Bihan-Duval EL, Babile R, Fernandez X, 2004. Breed differences in the biochemical determinism of ultimate $\mathrm{pH}$ in breast muscles of broiler chickens. A key role of AMP deaminase. Poultry Sci 83:144551.

Shantha NC, Decker EA, 1994. Rapid, sensitive, iron-based spectrophotometric methods for determination of peroxide values of food lipids. J AOAC Int 77:421-4.

Van Hoff J, 1979. Influence of ante- and peri- mortem factors on biochemical and physical characteristics of turkey breast muscle. Vet Quart 1:29-36.

Velarde A, Rodriguez P, Fuentes C, Llonch P, Von Holleben K, Von Wenzlawowicz M, Anil H, Miele M, Cenci Goga B, Lambooij B, Zivotofsky A, Gregory N, Bergeaud-Blackler F, Dalmau A, 2010. DIALREL report. Improving animal welfare during religious slaughter: recommendations for good practice. Available from: www.dialrel.eu/images/ ecom-light.pdf

Von Holleben K, von Wenzlawowicz M, Gregory N, Anil H, Velarde A, Rodriguez P, Cenci Goga B, Catanese B, Lambooij B, 2010. Report on good and adverse practices: animal welfare concerns in relation to slaughter practices from the viewpoint of veterinary sciences. Available from: http://www.vetjournal.it/archivio_pdf/2 010/4069.pdf

Xu L, Zhang L, Yue HY, Wu SG, Zhang HJ, Ji F, Qi GH, 2011. Effect of electrical stunning current and frequency on meat quality, plasma parameters, and glycolytic potential in broilers. Poultry Sci 90:1823-30. 